\title{
Radiation Hybrid Map Spanning the Huntington Disease Gene Region of Chromosome 4
}

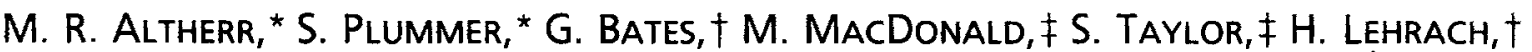 \\ A.-M. Frischauf, $\dagger$ J. F. GuSELla, $\ddagger$ M. BOEHNKE, $§$ AND J. J. WASMUTH ${ }^{\star, 1}$ \\ *Department of Biological Chemistry, University of California, Irvine, California 92717; †Impcrial Cancer Research Fund, P.O. Box \\ 123, Lincoln's Inn Fields, London WC2A 3PX, England; $¥$ Neuroscience Center, Massachusetts General Hospital, Building 149, \\ 13th Street, Charlestown, Massachusetts 02129; and §Department of Biostatistics, University of Michigan, \\ 109 South Observatory, Ann Arbor, Michigan 48109 \\ Received February 12, 1992; revised April 20, 1992
}

Radiation hybrid (RH) mapping was used to construct a map of 11 markers in the distal $4 \mathrm{Mb}$ of the short arm of chromosome 4 , the region containing the Huntington disease gene. Two different methods for deriving the order of the markers were compared and both arrived at the same order as being the most likely. This order is also consistent with both the physical map constructed using pulsed-field gel electrophoresis (PFGE) and the meiotic linkage map. Comparing the RH map to the map determined by PFGE provided the means to equate RH map units (centirays) with actual physical distance in kilobases of DNA. In addition, a simple procedure for reducing the complexity of human DNA in radiation hybrids is described. One cell line isolated using this procedure contains, as its only human DNA, $\sim 2 \mathrm{Mb}$ surrounding the Huntington disease gene. @1 1992 Academic Press, Inc.

\section{INTRODUCTION}

Radiation hybrid $(\mathrm{RH})$ mapping is a somatic cell genetic technique for constructing physical maps over tens of millions of basepairs of DNA at approximately $50 \mathrm{~Kb}$ resolution (Cox et al., 1990). In many respects, RH mapping is the physical mapping equivalent of meiotic mapping; the frequency of breakage or recombination between loci is directly related to the distance between them. In contrast to meiotic mapping, however, loci do not have to be polymorphic for $\mathrm{RH}$ mapping. In this report, we describe the construction of an RH map of 11 loci in the distal $4 \mathrm{Mb}$ of the short (p) arm of chromosome 4 , the region containing the Huntington disease (HD) gene. An RH map of this region is particularly useful in several respects:

1. It provided a way to correlate or equate $\mathrm{RH}$ map units (centirays or $\mathrm{cR}$ ) with actual physical distances separating loci in kilobases of DNA as a long-range restriction map of this region has been compiled by using PFGE (Bucan et al., 1990; Bates et al., 1991).

\footnotetext{
${ }^{1}$ To whom correspondence should be addressed.
}

2. Since one locus included in the RH map of distal $4 \mathrm{p}$ is within $300 \mathrm{~kb}$ of the telomere, the map provided data concerning the effect of the telomere on the retention of loci very near the ends of chromosomes.

3. The RH map could be used to predict the size of a gap that currently exists in the PFGE map of this region.

4. A region between two markers placed on the $\mathrm{RH}$ map, D4S10 and D5S125, has been shown to be a "hot spot" for meiotic recombination (Allitto et al., 1991). An $\mathrm{RH}$ map of this same region showed that the much higher than normal frequency of meiotic recombination was not correlated with a higher than average frequency of radiation-induced breakage.

In addition, two different methods for analyzing the data and constructing the $\mathrm{RH}$ map were compared. Interestingly, both methods arrived at the same order of loci as being the most likely, which is in agreement with the physical map determined by PFGE studies (Bucan et al., 1990; Bates et al., 1991). In addition to being mapping reagents, individual radiation hybrids with small, defined segments of the human genome provide a means to selectively clone DNA from specific regions. For example, Doucette-Stamm et al. (1991) described a microcell, irradiation, refusion procedure for deriving radiation hybrids that retain, under selective pressure, just the distal portion of $4 \mathrm{p}$. This cell line was used to isolate 14 new DNA clones from the Huntington disease gene candidate region. In this report we describe a simple procedure for reducing the amount of human DNA in radiation hybrids that does not involve any direct selection. This technique is useful for any set of radiation hybrids for any chromosome and allows the isolation of cell lines that retain single human DNA fragments from a region of interest.

\section{MATERIALS AND METHODS}

Isolation of radiation hybrids. The isolation of the 109 radiation hybrids used in these studies has been described (Warrington $e t$ al., 1991). The radiation hybrids were generated from the human-Chinese hamster cell hybrid HHW 661, which retains a derivative chromosome 5 [4pter-4p15.1::5p14-5qter] as its only human DNA (Was- 
muth et al., 1986). The region of chromosome 4 (p15.1-pter) present on this derivative chromosome includes the HD gene and the linked genetic markers (Smith et al., 1988; Lin et al., 1991).

Polymerase chain reaction. The presence or absence of each of 11 different markers from distal $4 \mathrm{p}$ in the 109 radiation hybrids was determined by PCR. Table 1 lists the loci that were tested, including clone names, HGMW-approved symbols, and the retention frequency of each in the radiation hybrids. The sequences of oligonucleotide primer sets for each marker has been reported, as have the annealing temperatures (Gusella et al., 1992). PCR reactions were carried out exactly as previously described (Warrington et al., 1991). The PCR primer sets for each locus were designed from genomic DNA sequence, and none were conserved in Chinese hamster, making the scoring of the radiation hybrids very straightforward.

Two-point and four-point analysis of $R H$ data. The relative distances between and the order of the 11 loci were determined using both two-point and four-point analysis programs as described by Cox et al. (1990). The distances between markers is reported in $\mathrm{cR}_{6500}$, where 6500 represents the radiation dose (in rads) the irradiated parent was exposed to in constructing the set of radiation hybrids. $\mathbf{c K}_{6500}$ is abbreviated as $\mathrm{cR}$ throughout the text.

Maximum likelihood multipoint analysis of $R H$ data. The 4p RH mapping data were also analyzed using a maximum likelihood multipoint approach (Boehnke et al., 1991). This approach makes use of data on all loci simultaneously, including information on partially typed hybrids. Like the two-locus method of Cox et al. (1990), the multipoint method assumes that breakage occurs at random along the chromosome and that fragments are retained independently. In the $N$-locus case, the likelihood of the RH data is a function of $N-1$ breakage probabilities $\theta_{i}$ between adjacent loci $i$ and $i+1$ and one or more retention probabilities for the various fragments that result. In the current analysis, we assume that all fragments have the same probability $r$ of being taken up in a radiation hybrid.

For a given order, breakage and retention probabilities are estimated by those values that maximize the likelihood of the $\mathrm{KH}$ mapping data. Orders can be compared by their maximum likelihoods, the order with the largest maximum likelihood being best supported by the data. Since it is not practical to consider all $N ! / 2$ locus orders explicitly, we used a branch-and-bound algorithm to identify the best locus order. Branch and bound guarantees that the best locus order is found, but requires explicit consideration of only a small subset of the possible orders.

Refusion of radiation hybrids to reduce the amount of human DNA. The radiation hybrid XZH 147 was fused with the $\mathrm{CHO}$ cell line UCW 932 in monolayer culture using polyethylene glycol as described previously (Wasmuth et al., 1981). UCW 932 has a mutation in the I.ARS gene, which renders leucyl-tRNA synthetase thermolobile and the cell line nonviable at $39^{\circ} \mathrm{C}$ (Thompson et al., 1973; Wasmuth and Chu, 1980). The temperature-sensitive phenotype is recessive. The cell line was also selected as being resistant to $1 \mathrm{~m} M$ ouabain, which behaves as a dominant selectable marker (Baker et al., 1974). The radiation hybrids are temperature resistant and sensitive to concentrations of ouabain above $0.1 \mathrm{mM}$. One-day postfusion, the cells were transferred to $39^{\circ} \mathrm{C}$ (to select against the UCW 932 parent) in medium with $1 \mathrm{mM}$ ouabain (to select against the XZH 147 parent). Only hybrids between the two cell lines are viable. Independent hybrid clones were isolated and maintained at $39^{\circ} \mathrm{C}$.

Fluorescence in situ hybridization. In situ hybridization was performed as described previously, using either total human DNA or a chromosome 4-specific plasmid library as the biotinylated probe (Altherr et al., 1991; Collins et al., 1991).

\section{RESULTS}

\section{Ordering of Markers Using Two-Point and Multipoint Methods}

The presence or absence of the 11 loci from distal $4 \mathrm{p}$ in 109 radiation hybrids was determined by PCR as described under Materials and Methods. The various markers were nonselectively retained in $22-29 \%$ of the radiation hybrids, as shown in Table 1 . The data were
TABLE 1

\section{Markers Placed on the RH Map}

\begin{tabular}{lcc}
\hline Locus & $\begin{array}{c}\text { Probe from which } \\
\text { primers were designed }\end{array}$ & $\begin{array}{c}\text { Retention frequency } \\
\text { in hybrids }\end{array}$ \\
\hline D4S10 & G8 & 0.26 \\
D4S125 & YNZ32 & 0.24 \\
D4S180 & L19 & 0.22 \\
D4S95 & BS674 & 0.26 \\
D4S43 & C9A & 0.25 \\
D4S166 & L6 & 0.27 \\
FGFR3 & BS385 HA & 0.23 \\
D4S168 & E4 & 0.24 \\
D4S97 & BS854 & 0.28 \\
D4S115 & 252 & 0.28 \\
D4S90 & CD2 & 0.23 \\
\hline
\end{tabular}

Note. The sequences of the oligonucleotide primer sets for each locus have been described, as have the PCR conditions (Gusella et al., 1992).

analyzed using two-point and four-point analysis programs as described by Cox et al. (1990). Table 2 summarizes the two-point linkage data, including the distances between markers in centirays (cR), the estimates for $\theta$, and the lod scores (for marker pairs with lod scores over 3.0).

Initially, the order of the 11 loci was resolved by arranging them so that the sum of the distances between adjacent markers was minimized. The likelihood of one order over another for sets of four markers also aided in ordering the loci, as described by Cox et al. (1990). Figure 1 shows the predicted order of and distances between the 11 loci as determined by the two-point and four-point analyses. The loci D4S97 and D4S115 were not separated in any radiation hybrids, thus the order of these is arbitrary.

Recently, Boehnke et al. (1991) described a method for multipoint analysis of RH mapping that was also used to analyze the data for the 11 loci described above. Table 3 presents the maximum likelihood locus order and distance estimates for that order, together with all other locus orders with maximum likelihood no more than 1000 times less than the best order. The best locus order was the same as that arrived at using the approach described above. However, several other locus orders had maximum likelihoods only marginally smaller. The fact that some of the nearly best locus orders are not simple two-locus inversions stresses the importance of providing a list of the best locus orders, rather than simply listing comparisons of likelihoods for locus inversions, which was done for the map shown in Fig. 1. This latter practice can substantially overstate the evidence in favor of the best locus order. The most likely order arrived at by using both $\mathrm{RH}$ mapping methods is the same as the order determined by PFGE mapping (Bucan et al., 1990; Bates et al., 1991).

\section{Correlation between RH Map Units and Kilobases} of DNA

To equate $\mathrm{RH}$ map units (cR) with actual physical distances in kilobases of DNA, the $\mathrm{RH}$ map distances between adjacent loci were compared to the kilobases of 
TABLE 2

RH Map Analysis and Two-Point Distances

\begin{tabular}{|c|c|c|c|c|c|c|c|c|c|}
\hline \multirow{2}{*}{$\begin{array}{c}\text { Marker } \\
\text { A }\end{array}$} & \multirow{2}{*}{$\begin{array}{c}\text { Marker } \\
\text { B }\end{array}$} & \multicolumn{5}{|c|}{ No. of clones observed } & \multirow[b]{2}{*}{$\theta$} & \multirow[b]{2}{*}{$\mathrm{cR}_{6500}$} & \multirow[b]{2}{*}{ LOL } \\
\hline & & ++ & +- & -+ & -- & TOT & & & \\
\hline S97 & $\mathrm{S} 115$ & 28 & 0 & 0 & 69 & 97 & 0 & 0 & 0 \\
\hline $\mathrm{S} 166$ & $\mathrm{~S} 43$ & 25 & 2 & 0 & 72 & 99 & 0.0521 & 5 & 20.64 \\
\hline $\mathrm{S} 115$ & $\mathrm{~S} 168$ & 22 & 2 & 0 & 69 & 93 & 0.0557 & 6 & 18.67 \\
\hline S97 & S168 & 22 & 2 & 0 & 68 & 92 & 0.0559 & 6 & 18.57 \\
\hline $\mathrm{S} 168$ & FGFR & 18 & 2 & 1 & 70 & 91 & 0.0916 & 10 & 15.18 \\
\hline $\mathrm{S} 95$ & $\mathrm{~S} 125$ & 23 & 3 & 1 & 72 & 99 & 0.1069 & 11 & 17.3 \\
\hline $\mathrm{S} 97$ & $\mathrm{~S} 166$ & 25 & 3 & 1 & 68 & 97 & 0.1020 & 11 & 17.89 \\
\hline $\mathrm{S} 125$ & $\mathrm{~S} 10$ & 23 & 1 & 3 & 72 & 99 & 0.1069 & 11 & 17.3 \\
\hline S95 & $\mathrm{S} 180$ & 22 & 4 & 0 & 73 & 99 & 0.1097 & 12 & 16.9 \\
\hline FGFR & $\mathrm{S} 43$ & 20 & 2 & 2 & 70 & 94 & 0.1155 & 12 & 15.37 \\
\hline S97 & FGFR & 21 & 4 & 0 & 68 & 93 & 0.1109 & 12 & 15.87 \\
\hline FGFR & S166 & 21 & 1 & 3 & 69 & 94 & 0.1122 & 12 & 15.89 \\
\hline $\mathrm{S} 180$ & $\mathrm{~S} 125$ & 21 & 1 & 3 & 74 & 99 & 0.1132 & 12 & 16.36 \\
\hline S115 & $\mathrm{S} 166$ & 25 & 3 & 2 & 69 & 99 & 0.1258 & 13 & 17.06 \\
\hline $\mathrm{S} 43$ & $\$ 95$ & 23 & 2 & 3 & 71 & 99 & 0.1320 & 14 & 16.24 \\
\hline S115 & FGFR & 21 & 4 & 1 & 68 & 94 & 0.1383 & 15 & 14.93 \\
\hline S97 & $\mathrm{S} 43$ & 23 & 5 & 1 & 68 & 97 & 0.1564 & 17 & 15.11 \\
\hline S95 & $\mathrm{S} 10$ & 23 & 3 & 3 & 70 & 99 & 0.1564 & 17 & 15.28 \\
\hline $\mathrm{S} 180$ & $\mathrm{~S} 10$ & 21 & 1 & 5 & 72 & 99 & 0.1646 & 18 & 14.5 \\
\hline $\mathrm{S} 168$ & $\mathrm{~S} 166$ & 20 & 2 & 4 & 67 & 93 & 0.1696 & 19 & 13.41 \\
\hline S168 & $\mathrm{S} 43$ & 19 & 3 & 3 & 68 & 93 & 0.1745 & 19 & 12.92 \\
\hline $\mathrm{S} 166$ & S95 & 23 & 4 & 3 & 69 & 99 & 0.1803 & 20 & 14.4 \\
\hline $\mathrm{S} 115$ & $\mathrm{~S} 43$ & 23 & 5 & 2 & 69 & 99 & 0.1801 & 20 & 14.44 \\
\hline $\mathrm{S} 43$ & $\mathrm{~S} 180$ & 20 & 5 & 2 & 72 & 99 & 0.1950 & 22 & 13.16 \\
\hline FGFR & S95 & 18 & 4 & 4 & 68 & 94 & 0.2277 & 26 & 11.05 \\
\hline $\mathrm{S} 43$ & $\mathrm{~S} 125$ & 20 & 5 & 4 & 70 & 99 & 0.2440 & 28 & 11.61 \\
\hline S166 & $\mathrm{S} 180$ & 20 & 7 & 2 & 70 & 99 & 0.2432 & 28 & 11.72 \\
\hline $\mathrm{S} 166$ & $\mathrm{~S} 90$ & 20 & 7 & 3 & 69 & 99 & 0.2669 & 31 & 10.98 \\
\hline $\mathrm{S} 43$ & S90 & 19 & 6 & 4 & 70 & 99 & 0.2748 & 32 & 10.52 \\
\hline S97 & S95 & 21 & 7 & 4 & 65 & 97 & 0.2837 & 33 & 10.47 \\
\hline S43 & $\mathrm{S} 10$ & 20 & 5 & 6 & 68 & 99 & 0.2904 & 34 & 10.27 \\
\hline $\mathrm{S} 115$ & $\mathrm{~S} 90$ & 20 & 8 & 3 & 68 & 99 & 0.2895 & 34 & 10.37 \\
\hline $\mathrm{S} 168$ & S95 & 17 & 5 & 5 & 66 & 93 & 0.2867 & 34 & 9.18 \\
\hline $\mathrm{S} 166$ & S125 & 20 & 7 & 4 & 68 & 99 & 0.2901 & 34 & 10.3 \\
\hline $\mathrm{S} 97$ & $\mathrm{~S} 90$ & 20 & 8 & 3 & 66 & 97 & 0.2931 & 35 & 10.2 \\
\hline FGFR & $\mathrm{S} 180$ & 16 & 6 & 4 & 68 & 94 & 0.3020 & 36 & 8.77 \\
\hline $\mathrm{S} 115$ & S95 & 21 & 7 & 5 & 66 & 99 & 0.3053 & 36 & 10.03 \\
\hline FGFR & $\mathrm{S} 10$ & 16 & 6 & 5 & 67 & 94 & 0.3131 & 38 & 8.3 \\
\hline FGFR & $\mathrm{S} 90$ & 16 & 6 & 5 & 67 & 94 & 0.3272 & 40 & 8.19 \\
\hline S166 & $\mathrm{S} 10$ & 20 & 7 & 6 & 66 & 99 & 0.3348 & 41 & 9.07 \\
\hline FGFR & $\mathrm{S} 125$ & 15 & 7 & 5 & 67 & 94 & 0.3516 & 43 & 7.27 \\
\hline S97 & $\mathrm{S} 180$ & 18 & 10 & 3 & 66 & 97 & 0.3502 & 43 & 8.31 \\
\hline $\mathrm{S} 168$ & S90 & 15 & 7 & 5 & 66 & 93 & 0.3594 & 45 & 7.17 \\
\hline $\mathrm{S} 97$ & $\mathrm{~S} 10$ & 19 & 9 & 5 & 64 & 97 & 0.3611 & 45 & 8.02 \\
\hline $\mathrm{S} 115$ & $\mathrm{~S} 180$ & 18 & 10 & 4 & 67 & 99 & 0.3727 & 47 & 7.93 \\
\hline $\mathrm{S} 168$ & $S 10$ & 15 & 7 & 6 & 65 & 93 & 0.3728 & 47 & 6.75 \\
\hline $\mathrm{S} 168$ & $\mathrm{~S} 180$ & 14 & 8 & 5 & 66 & 93 & 0.3952 & 50 & 6.27 \\
\hline $\mathrm{Sg7}$ & $\mathrm{S} 125$ & 18 & 10 & 5 & 64 & 97 & 0.3953 & 50 & 7.2 \\
\hline S95 & $\mathrm{S} 90$ & 17 & 9 & 6 & 67 & 99 & 0.4062 & 52 & 6.97 \\
\hline $\mathrm{S} 115$ & $\mathrm{~S} 10$ & 19 & 9 & 7 & 64 & 99 & 0.4071 & 52 & 7.17 \\
\hline $\mathrm{S} 168$ & $\mathrm{~S} 125$ & 14 & 8 & 6 & 65 & 93 & 0.4132 & 53 & 5.84 \\
\hline $\mathrm{S} 115$ & $\mathrm{~S} 125$ & 18 & 10 & 6 & 65 & 99 & 0.4164 & 54 & 6.88 \\
\hline $\mathrm{S} 180$ & $\mathrm{~S} 90$ & 15 & 7 & 8 & 69 & 99 & 0.4313 & 56 & 6.17 \\
\hline $\mathrm{S} 10$ & S90 & 16 & 10 & 7 & 66 & 99 & 0.4604 & 62 & 5.73 \\
\hline $\mathrm{S} 125$ & S90 & 15 & 9 & 8 & 67 & 99 & 0.4742 & 64 & 5.35 \\
\hline
\end{tabular}

Note. For each marker pair, ++ indicates the number of hybrids containing markers $\mathrm{A}$ and $\mathrm{B},+-$ indicates that marker $\mathrm{A}$ is present and marker $B$ is absent, - + indicates that marker $A$ is absent and marker $B$ is present, and - - indicates that neither marker is present. $\theta$ denotes the estimated frequency of breakage, $\mathrm{cR}_{6500}$ is the estimated map distance, and the lod score is a measure of the likelihood that two markers are linked (Cox et al., 1990). 


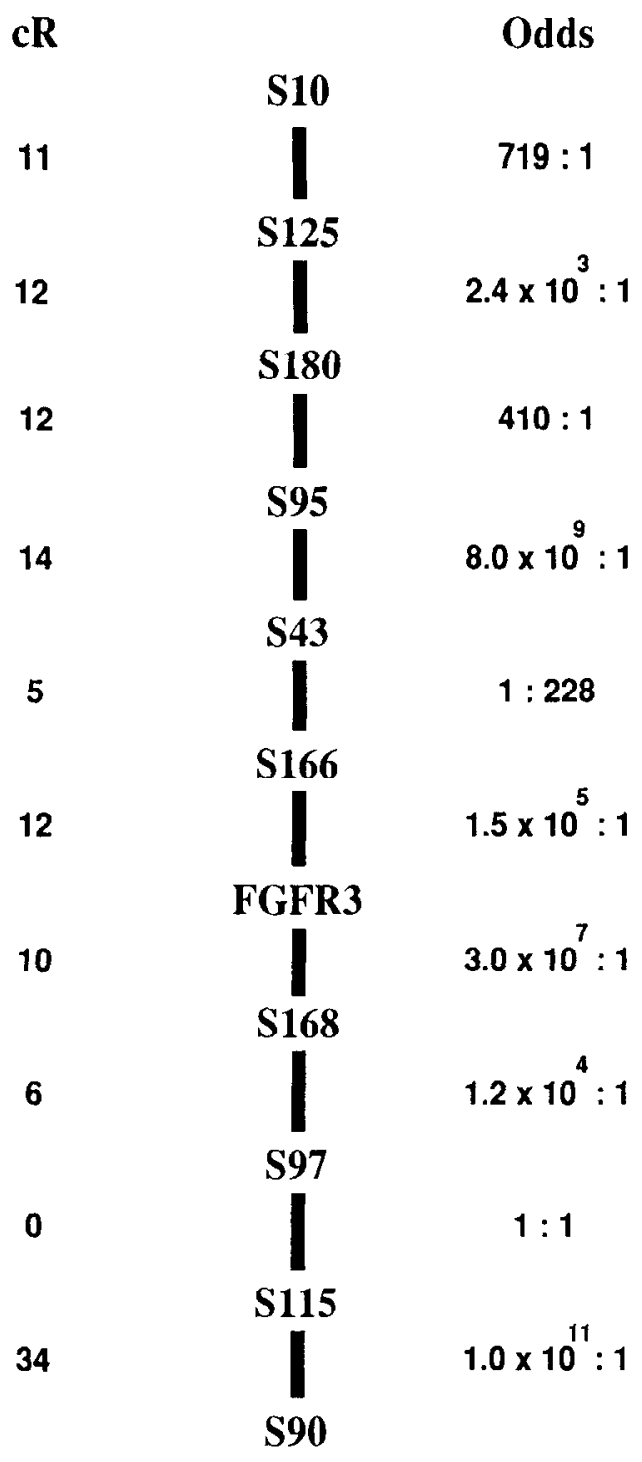

FIG. 1. Radiation hybrid map as determined by two-point and four-point methods. The distances between markers (left) are expressed in $\mathrm{cR}_{6500}$. The order was determined as described in the text. The numbers on the right are the odds of the given order versus the likelihood of the order in which a given pair of markers is inverted. Four-point analysis was performed on each set of four markers, and the odds for any two middle markers was compared to the odds where the middle markers were inverted. The odds for the two most distal markers and the two most proximal markers were determined by using the four most distal and proximal markers, respectively, and inverting the position of the two markers at each end of the map.

DNA separating them based upon extensive long-range restriction maps of this region (Bucan et al., 1990; Bates et al., 1991). Figure 2 shows the distances between markers in kilobases and centirays using data from both the two-point and multipoint methods. Taking the average for each pair of adjacent loci, $1 \mathrm{cR}$ corresponds to 32 $\mathrm{kb}$ of DNA using the two-point data or $27 \mathrm{~kb}$ of DNA using the multipoint data. In addition, as also shown in Fig. 2, the relative distances between markers, whether determined by PFGE, two-point analysis, or multipoint analysis, are within twofold of one another for most pairs of adjacent markers.

Two other points concerning the $\mathrm{RH}$ map of this region are worth noting. The retention frequency for the
11 loci in the $\mathrm{RH}$ hybrids varies only from 22 to $29 \%$ with no significant gradation from the most telomeric locus (D4S90) to the most centromeric (D4S10). Since $\mathrm{D} 4 \mathrm{~S} 90$ is only $\sim 300 \mathrm{~kb}$ from the telomere of $4 \mathrm{p}$, this result suggests that DNA fragments very near telomeres are no more or less likely to be retained in $\mathrm{RH}$ hybrids than the more proximal loci. In addition, the retention frequencies in this set of radiation hybrids for 13 loci on the long arm of chromosome 5 (most of which are tens of megabases from the telomere) are comparable (16-28\%) to those observed for the distal $4 \mathrm{p}$ markers, further suggesting the lack of a "telomere" effect on retention of loci in radiation hybrids (Warrington et al., 1991). Second, the region of greatly increased meiotic recombination, which is between $\mathrm{D} 4 \mathrm{~S} 10$ and $\mathrm{D} 4 \mathrm{~S} 125$, does not correlate with an increased likelihood of radiation-induced breakage. The genetic distance between these loci, which are less than $500 \mathrm{~kb}$ apart, is $\sim 3.5 \mathrm{cM}$ or close to 10 times the overall average for the human genome (Allitto et al., 1991). However, the relationship between kilobases of DNA and the centiray distance between these loci using two-point data $(43 \mathrm{~kb} / \mathrm{cR})$ is slightly higher than the overall average for the entire region $(32 \mathrm{~kb} / \mathrm{cR})$, indicating a lower than average frequency of breakage. Using the multipoint data, the kilobase to centiray relationship between D4S10 and D4S125 is slightly lower $(17 \mathrm{~kb} / \mathrm{cR})$ than the average for the region $(27 \mathrm{~kb} / \mathrm{cR})$. However, this difference is nowhere near the 10-fold increased frequency of meiotic recombination.

\section{Estimating the Size of a Gap in the PFGE Map of Distal $4 p$}

There is currently one gap, of unknown size, in the long-range restriction map from $\mathrm{D} 4 \mathrm{~S} 10$ to the $4 \mathrm{p}$ telomere. The closest markers flanking this gap are D4S168 on the proximal side and D4S115 on the distal side (Bates et al., 1991). The two-point centiray distance between these loci is $6 \mathrm{cR}$, which would correspond to 192 $\mathrm{kb}$ based upon the average of $32 \mathrm{~kb} / \mathrm{cR}$. Thus, the $\mathrm{RH}$ map would predict that the gap in the PFGE map is small. In fact, if there is no gap in the PFGE map, existing data indicate the distance between these loci to be $175 \mathrm{~kb}$ (G. Bates, personal communication). It is likely that a high density of very well cut restriction sites within this region have precluded closure of the PFGE map. Until very recently there was a second, more proximal gap in the long-range restriction map (between D4S95 and D4S180), which recently was closed and shown to be $\sim 480 \mathrm{~kb}$ (Bates et al., 1991). Before this distance was established, the centiray distance between these loci $(12 \mathrm{cR})$ predicted the gap to be $\sim 385 \mathrm{~kb}$. In regions of the genome that have a very high frequency of sites for rare-cutting enzymes, like distal $4 p$, the compilation of a restriction map over several megabases can be very difficult. In regions such as this, an RH map can provide reasonable estimates of kilobase distances separating loci, assuming one has enough markers and PFGE mapping data to be able to establish a good correlation between RH map units and actual physical distance. 
TABLE 3

Maximum Likelihood Locus Orders for the Multipoint Analysis

\begin{tabular}{|c|c|c|c|c|c|c|c|c|c|c|c|c|}
\hline & & & & & & Locus orde & & & & & & $\begin{array}{c}\text { Relative } \\
\text { likelihood }\end{array}$ \\
\hline & 35 & 5 & & 8 & 11 & 5 & 14 & 12 & 12 & 11 & 29 & \\
\hline S90 & S115 & & S97 & $\mathrm{S} 168$ & FGFR3 & S166 & $\mathrm{S} 43$ & $\mathrm{~S} 95$ & $\mathrm{~S} 180$ & $\mathrm{~S} 125$ & $\mathrm{~S} 10$ & $1: 1$ \\
\hline S90 & $\mathrm{S} 115$ & & $\mathrm{~S} 97$ & $\mathrm{~S} 168$ & FGFR3 & S166 & $\mathrm{S} 43$ & S95 & S125 & S10 & $\mathbf{S 1 8 0}$ & $30: 1$ \\
\hline S90 & S115 & & S97 & S168 & FGFR3 & S166 & $\mathrm{S} 43$ & S95 & $\mathbf{S 1 0}$ & S125 & S180 & $32: 1$ \\
\hline S90 & FGFR3 & & S168 & S115 & S97 & $\mathrm{S} 166$ & $\mathrm{~S} 43$ & S95 & $\mathrm{S} 180$ & $\mathrm{~S} 125$ & $\mathrm{~S} 10$ & $75: 1$ \\
\hline S90 & S115 & & S97 & $\mathrm{S} 168$ & FGFR3 & S166 & $\mathrm{S} 43$ & S95 & $\mathrm{S} 180$ & S10 & $\mathbf{S 1 2 5}$ & $88: 1$ \\
\hline S90 & S115 & & S97 & $\mathrm{S} 168$ & FGFR3 & S166 & $\mathrm{S} 43$ & 180 & $\mathbf{5 9 5}$ & $\mathrm{S} 125$ & $\mathrm{~S} 10$ & $162: 1$ \\
\hline S90 & \$115 & & $\mathbf{S 9 7}$ & S168 & FGFR3 & $\mathbf{S 4 3}$ & S166 & $\mathrm{S} 95$ & $\mathrm{~S} 180$ & $\mathrm{~S} 125$ & $\mathrm{~S} 10$ & $186: 1$ \\
\hline S90 & $\mathrm{S} 115$ & & S97 & $\mathrm{S} 168$ & FGFR3 & $\mathrm{S} 166$ & $\mathrm{~S} 43$ & S95 & $\mathbf{S 1 2 5}$ & $\mathbf{S 1 8 0}$ & $\mathrm{S} 10$ & 253:1 \\
\hline
\end{tabular}

Note. Relative likelihood compares the maximum likelihood for the given locus order to that for the overall maximum likelihood order. Boldface numbers indicate inversions of two or more loci relative to the best locus order; boxed boldface numbers indicate more complex modifications. The order of $\mathrm{S} 115$ and $\mathrm{S} 97$ is arbitrary. Numbers listed above the best locus order are estimates of the distances between the loci (in centirays).

Reducing the Complexity of Human DNA in Radiation Hybrids by Refusion

In addition to providing physical mapping information, selected RH hybrids provide a simple means to cloning human DNA from small, specific regions of particular interest. In this case, the region of interest is between the two closest markers flanking the HD gene, $\mathrm{D} 4 \mathrm{~S} 126$ and D4S168. For example, one RH hybrid we characterized (XZH 147) is positive for loci from D4S168 to D4S95, but negative for other markers from $4 \mathrm{p}$ tested. If this were the only human DNA in the cell line, it would represent a very enriched source of most of the DNA in the HD region, which could be recovered either by interspersed-repeat sequence PCR (IRS-PCR) or construction of a genomic library. However, like the majority of RH hybrids we have characterized, XZH 147 was found to retain multiple (six to seven) fragments of human DNA, as determined by fluorescent in situ hybridization with total human DNA (Fig. 3A). Only one of the fragments is derived from the chromosome 4 portion of the derivative human chromosome in the parent (HHW 661) of the radiation hybrids, as determined by chromosome "painting" with a chromosome 4-specific plasmid library (Fig. 3B).

In an attempt to derive a cell line containing the fragment of distal 4p exclusively, the RH hybrid XZH 147 was refused (without irradiation) to a Chinese hamster ovary $(\mathrm{CHO})$ cell line with two selectable genetic markers. One of the markers, which is recessive, results from a mutation in the gene encoding leucyl-tRNA synthetase, which renders the cell line nonviable at $39^{\circ} \mathrm{C}$ (Thompson et al., 1973). The second marker, resistant to $1 \mathrm{~m} M$ ouabain, is a dominant selectable marker (Baker et al., 1974). Secondary hybrids between the XZH 147 and the $\mathrm{CHO}$ cell lines were selected as described under Materials and Methods.

The rationale for this approach is as follows: The hybrids between the two cell lines are, for all practical purposes, intraspecific Chinese hamster $\times$ Chinese hamster cell hybrids, which are usually pseudotetraploid. That is, they retain most of the chromosomes from each parent but usually have a chromosome number $10-20 \%$ less than a true tetraploid karyotype, apparently because a few chromosomes from one or both parents segregate after fusion. If the chromosomes from the XZH parent with the human fragments are as likely to segregate after refusion as any other chromosomes, it should be possible to identify "secondary" hybrids in which, by chance, the chromosome with the human fragment of interest is present without the chromosomes containing the unwanted human fragments.

Sixteen independent hybrids between the two cell lines were isolated and tested immediately after cloning for the presence of two loci in the $4 \mathrm{p}$ segment retained in

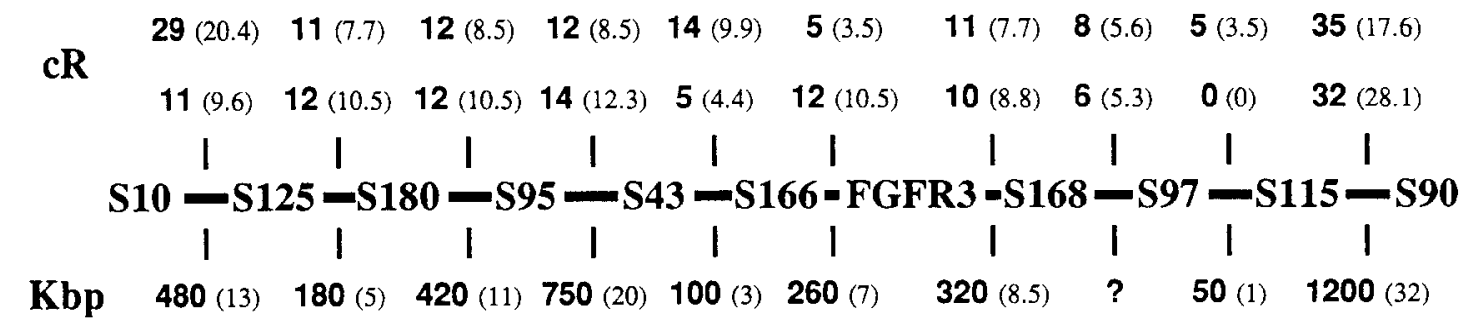

FIG. 2. Distances between markers as determined by PFGE, two-point analysis and multipoint analysis. The physical distance between adjacent markers in kb of DNA is shown below each pair of markers. The $\mathrm{cR}$ distance between markers, as determined by two-point analysis, is shown just above each pair of markers. The $\mathrm{cR}$ distances determined by multipoint analysis are the uppermost numbers. The number in parentheses represent the relative distances between adjacent markers as determined by the different methods. The distance between D4S10 and D4S90 was set at 100; the fraction of this that each interval represented was then calculated. 
XZH 147 (D4S43 and D4S95). Ten of the 16 hybrids retained the $4 \mathrm{p}$ markers, and these were then tested by IRS-PCR to determine which contained the least amount of human DNA. Two of the 10 hybrids that had the least complex patterns of human fragments amplified by IRS-PCR were then examined by fluorescent in situ hybridization using total human DNA as a probe. One of these secondary hybrids contained only a single fragment of human DNA, as shown in Fig. 3C. Thus, the simple refusion technique, together with the PCR assays, represents an easy way to produce and characterize $\mathrm{RH}$ hybrids with single, defined segments of the human genome. DNA from one of the secondary hybrids has been used along with IRS-PCR to isolate several human DNA fragments, all of which map to the expected region of $4 \mathrm{p}$. Although most of the DNA in the HD gene region has already been cloned, the technique of reducing the complexity of human DNA in RH hybrids via refusion provides a convenient means to developing cell hybrid reagents to allow selective cloning of human DNA from other regions of particular interest where very little cloned DNA is available.

\section{DISCUSSION}

The two different methods used to construct the $\mathrm{RH}$ map of distal $4 \mathrm{p}$ both arrived at the same order as being most likely. However, several other orders had likelihoods not much lower than the best. In constructing maps using $\mathrm{RH}$ hybrids, the two-point/four-point method becomes cumbersome with more than 10 or so markers, while the multipoint method can easily handle at least twice this number. However, it would seem important to analyze the data using both methods, since the two-point approach requires a more careful examination of the raw data.

One particular advantage to compiling an $\mathrm{RH}$ map of distal $4 p$ is that it provided an easy and accurate means of equating centirays to real physical distances in kilobases of DNA, since an extensive PFGE map of this region exists (Bucan et al., 1990; Bates et al., 1991). This information was useful for estimating the size of an apparently small gap in the PFGE map. In addition, this same set of radiation hybrids is being used to compile a physical map of the long arm of chromosome 5 (5q) (Warrington et al., 1991). Even though an extensive

FIG. 3. In situ hybridization of biotinylated total human or chromosome 4-specific DNA to a radiation hybrid and a secondary refusion hybrid. (A) Metaphase chromosome preparations from radiation hybrid XZH 147 were hybridized with labeled total human DNA. Sixseven different fragments of human DNA are visible. (B) Metaphase chromosome preparations from XZH 147 were hybridized with labeled DNA prepared from a human chromosome 4-specific plasmid library (Collins et al., 1991). Only one of the fragments in A shows hybridization to the chromosome 4-specific probe, and it appears to be telomeric. (C) Metaphase chromosome preparations from a secondary refusion hybrid (derived from XZH 147) hybridized with labeled total human DNA. Only one human DNA fragment is detected, and it appears to be the same telomeric fragment detected in XZH 147 with the chromosome 4-specific label, as in $\mathbf{B}$.
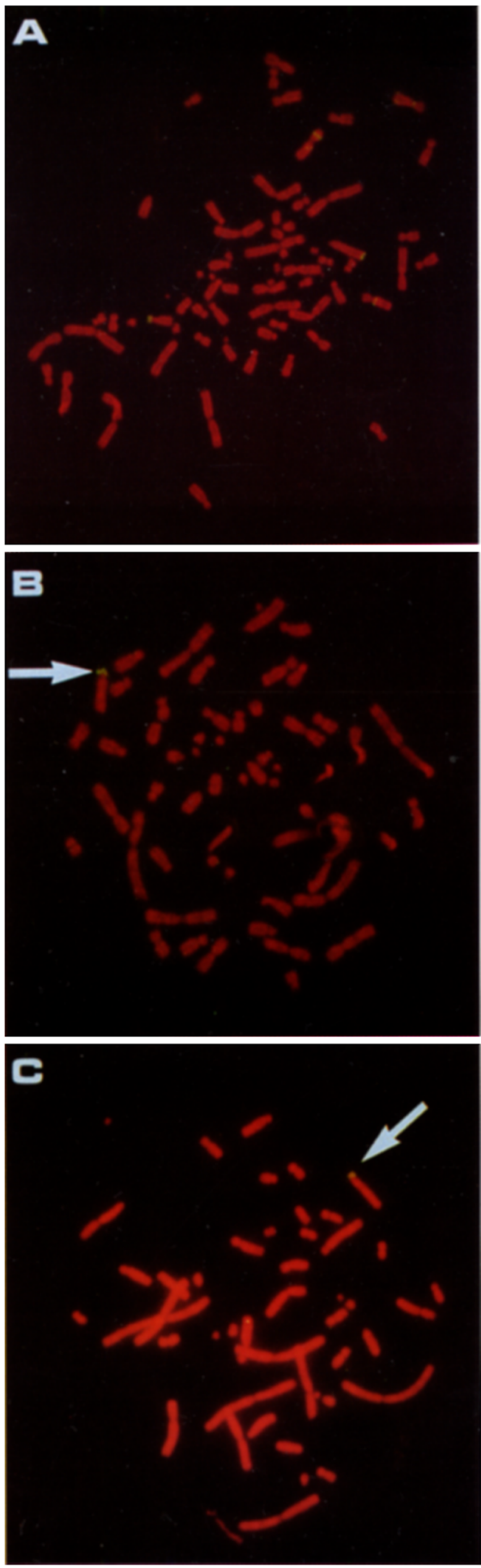
PFGE map does not exist for any region of $5 q$, we can estimate the real physical distances between markers using the centiray to kilobase relationship determined for $4 p$. As the map of $5 q$ becomes more refined, it will be interesting to determine whether the relationship between a centiray and a kilobase of DNA is consistent over most of the derivative chromosome 5 retained by the irradiated parent of these hybrids.

The refusion procedure described here for reducing the complexity of human DNA in radiation hybrids is applicable to any set of radiation hybrids for any chromosome. A large number of refusion, secondary hybrids can be screened with ease using PCR and just a few cells. Only those clones that are the best candidates for having the region of interest without any "extraneous" human DNA need to be analyzed by in situ hybridization. We have used the same technique for isolating refusion hybrids that contain single, small fragments of 5q, including one with just the region surrounding the gene for spinal muscular atrophy (Brzustowicz et al., 1990; Melki et al., 1990) and one with just the region surrounding the gene for Treacher Collins syndrome (Dixon et al., 1991; Jabs et al., 1991).

\section{ACKNOWLEDGMENTS}

This work was supported in part by NIH Grants NS25631 and HG00320 to J.J.W., NIH Grants NS16367 and HG00169 to J.F.G., the Huntington Disease Collaborative Research Group (Hereditary Discase Foundation), the Joan and William A. Schreyer-Merrill Lynch Research Foundation to Cure Huntington Disease, NIH Grants R29HG00376 and P30-HG00290 to M.B., and a grant from the Huntington Disease Society of America to M.A.

\section{REFERENCES}

Allitto, B. A., MacDonald, M. E., Bucan, M., Richards, J., Romano, D., Whaley, W. L., Falcone, B., Ianazzi, J., Wexler, N. S., Wasmuth, J. J., Collins, F. S., I.ehrach, H., Haines, J. L., and Gusella, J. F. (1991). Increased recombination adjacent to the Huntington's disease-linked D4S10 marker. Genomics 9: 104-112.

Altherr, M. R., Bengtsson, U., Elder, F. F. B., Ledbetter, D. H., Wasmuth, J. J., McDonald, M. E., Gusella, J. F., and Greenberg, F. (1991). Molecular confirmation of Wolf-Hirschhorn syndrome with a subtle translocation of chromosome 4. Am. J. Hum. Genet. 49: 1235-1242.

Baker, R. M., Brunette, D. M., Mankovitz, R., Thompson, L. H., Whitmore, G. F., Siminovich, L., and Till, J. E. (1974). Ouabain-resistant mutants of mouse and hamster cells in culture. Cell 1: 9-21.

Bates, G. P., MacDonald, M. E., Baxendale, S., Youngman, S., Lin, C., Whaley, W. L., Wasmuth, J. J., Gusella, J. F., and I sehrach, H. (1991). Defined physical limits of the Huntington disease gene candidate region. Am. J. Hum. Genet. 49: 7-16.

Boehnke, M., Lange, K., and Cox, D. R. (1991). Statistical methods for multipoint radiation hybrid mapping. Am. J. Hum. Genet 49: 11741188.

Brzustowicz, L. M., Lehner, T., Castilla, L. H., Penchaszadeh, G. K., Wilhelmsen, K. C., Daniels, R., Davies, K. E., Leppert, M., Ziter, F., Wood, D., Dubowitz, V., Zerres, K., Hausmanowa-Petrusewicz, I., Ott, J., Munsat, T. L., and Gilliam, T. C. (1990). Genetic mapping of chronic childhood-onset spinal muscular atrophy to chromosome 5q11.2-13.3. Nature 344: 540-541.

Bucan, M., Zimmer, M., Whaley, W. L., Poutska, A., Youngman, S., Allitto, B. A., Ormondroyd, E., Smith, B., Pohl, T. M., MacDonald, M., Bates, G. P., Richards, J., Volinia, S., Gilliam, T. C., Sedlacek, Z., Collins, F. S., Wasmuth, J. J., Shaw, D. J., Gusella, J. F., Frischauf, A.-M., and Lehrach, H. (1990). Physical maps of 4 p16.3, the area expected to contain the Huntington disease mutation. Genomics 6: 1-15.

Collins, C., Kuo, W. L., Segraves, R., Fuscoc, J., Pinkel, D., and Gray, J. W. (1991). Construction and characterization of plasmid libraries enriched in sequences from single human chromosomes. Genomics 11: $997-1006$.

Cox, D. R., Burmeister, M., Price, E. R., Kim, S., and Myers, R. M. (1990). Radiation hybrid mapping: A somatic cell genetic method for constructing high-resolution maps of mammalian chromosomes. Science 250: 245-250.

Dixon, M. J., Read, A. P., Donnai, D., Colley, A., Dixon, J., and Williamson, R. (1991). The gene for the Treacher Collins syndrome maps to the long arm of chromosome 5. Am. J. Hum. Genet. 49: $17-22$.

Doucette-Stamm, L. A., Riba, L., Handelin, B., Difilippantonio, M., Ward, D. C., Wasmuth, J. J., Gusella, J. F., and Housman, D. E. (1991). Generation and characterization of irradiation hybrids of human chromosome 4. Somat. Cell Mol. Genet. 17: 471-480.

Gusella, J. F., Altherr, M. R., McClatchey, A. I., Doucette-Stamm, L. A., Tagle, D., Plummer, S., Groot, N., Collins, F. S., Housman, D. E., Lehrach, H., MacDonald, M. E., Bates, G., and Wasmuth, J. J. (1992). Sequence-tagged sites (STSs) spanning $4 \mathrm{p} 16.3$ and the Huntington disease candidate region. Genomics 13: 75-80.

Jabs, E. W., Li, X., Coss, C. A., Taylor, E. W., Meyers, D. A., and Weber, J. L. (1991). Mapping the Treacher Collins syndrome locus to 5 q31.3 $\rightarrow$ q33.3. Genomics 11: 193-198.

Lin, C. S., Altherr, M., Bates, G., Whaley, W. L., Read, A. P., Harris, R., Lehrach, H., Wasmuth, J. J., Gusella, J. F., and MacDonald, M. E. (1991). New DNA markers in the Huntington's disease gene candidate region. Somat. Cell Mol. Genet. 17: 481-488.

Melki, J., Abdelhak, S., Sheth, P., Bachelot, M. F., Burlet, P., Marcadet, A., Aicaradi, J., Barois, A., Carriere, J. P., Fardeau, M., Fontan, D., Ponsot, G., Billette, T., Angelini, C., Barbosa, C., Ferriere, G., Lanzi, G., Ottolini, A., Babron, M. C., Cohen, D., Hanauer, A., Clerget-Darpoux, F., Lathrop, M., Munnich, A., and Frezal, J. (1990). Gene for chronic proximal spinal muscular atrophies maps to chromosome 5q. Nature 344: 767.

Smith, B., Skarecky, D., Bengtsson, U., Magenis, R. E., Carpenter, N., and Wasmuth, J. J. (1988). Isolation of DNA markers in the direction of the Huntington's disease gene from the G8 locus. Am. $J$. Hum. Genet. 42: 335.

Thompson, L. H., Harkins, J. L., and Stanners, C. P. (1973). A mammalian cell mutant with a temperature sensitive leucyl-transfer RNA synthetase. Proc. Natl. Acad. Sci. USA 70: 3094-3098.

Warrington, J. A., Hall, L. V., Hinton, L. M., Miller, J. N., Wasmuth, J. J., and Lovett, M. (1991). Radiation hybrid map of 13 loci on the long arm of chromosome 5. Genomics 11: 701-708.

Wasmuth, J. J., and Chu, L.-Y. (1980). Linkage in cultured Chinese hamster cells of two genes, emtB and leuS, involved in protein synthesis and isolation of cell lines with mutations in three linked genes. J. Cell Biol. 87: 697-702.

Wasmuth, J. J., Hill, J. M., and Vock, L. S. (1981). Identification and characterization of a third complementation group of emetine-resistant Chinese hamster cell mutants. Mol. Cell. Biol. 1: 58-65.

Wasmuth, J. J., Carlock, L. R., Smith, B., and Immken, L. L. (1986). A cell hybrid and recombinant DNA library that facilitate identification of poiymorphic loci in the vicinity of Huntington's disease gene. Am. J. Human Genet. 39: 397. 